\title{
Prevention of Latent National Aggression in the Course of Future Teacher Education
}

\author{
Valerian Faritovich Gabdulchakov ${ }^{1} \&$ Olga Vladimirovna Yashina ${ }^{1}$ \\ ${ }^{1}$ Kazan Federal University, Mezhlauka str., 1, Kazan, Russian Federation \\ Correspondence: Valerian Faritovich Gabdulchakov, Kazan Federal University, Mezhlauka str., 1, Kazan, 420111, \\ Russian Federation. E-mail: progabdulhakov@gmail.com
}

Received: September 25, 2014

Accepted: October 27, 2014 Online Published: December 20, 2014

doi:10.5539/ass.v11n2p270

URL: http://dx.doi.org/10.5539/ass.v11n2p270

\begin{abstract}
The basic principles of tolerance, respect for other cultures, readiness for cross-cultural dialogue, basic principles of productive bilingualism are introduced not at school or university, but in kindergarten (age 3-5). At this age, family (parents) and educators play a special role. However, it is in the kindergarten where kids are often badly influenced. The technology of preventing latent national aggression should give students the opportunity to participate in goal-setting, planning their pedagogical activity and its control; ensure their predicting of cross-cultural content, types and results of business or simulation games; when developing the methods of organization of stages in the game, it is necessary to consider the relationship between regulatory, cognitive and communicative components of anticipation. The technology should be based on multicultural content. The values of two cultures, two languages should be disclosed in this content, and positive situations of cross-cultural dialogue should be presented.
\end{abstract}

Keywords: tolerance, preschool education, technology of preventing national aggression

\section{Introduction}

Currently the problems of cross-cultural dialogue, tolerance development and national aggression prevention in the institutions' educational environment are the topic of discussion for many scholars (Sleeter, 1996; Einarsdóttir \& Perry, 2012; Kudryavtsev, 2011; Veraksa, 2011). But there are not many researches concerning this aggression prevention during preschool teachers' education (Gabdulchakov, 2011). In Russia multicultural education in kindergartens is only declarative. Actually it is either absent, or is formal. In recent years, national problems have intensified. People come to understand that this education should be lifelong.

Various authors in their research, monographs give different definitions for aggression and aggressiveness: human instinct to «defend the territory" (Lorenz, Ardri); as establishing domination (Morrison); as the reaction of a person on a hostile surrounding reality (Horni, Fromm). Very widespread are the theories associating aggression and frustration (Miller, Doob, Dollard).

National aggression is not expressed directly in the institutes of the Volga region. It is hidden (latent). This allows holding the balance and stability in political, economic, social-cultural and education spheres. However, in case of the slightest disbalance in these spheres, aggression may become overt with unpredictable outcome.

Historically, aggression has been evaluated in a variety of ways. Among them, the Buss-Durkee Hostility Inventory (Buss \& Durkee, 1957) has been one of the most popular questionnaires. On the basis of this previous work, Buss and Perry proposed in 1992 a psychometrically improved and updated measure of aggression: The Aggression Questionnaire (AQ). The original version of the AQ contains 29 items and is designed to assess four dispositional dimensions of aggression: Physical Aggression, Verbal Aggression, Anger, and Hostility. Physical and Verbal Aggression involve hurting or harming others and represent the instrumental or motor component of the behavior. Anger involves physiological excitation and represents the emotional component of the behavior. Finally, hostility consists of feelings of ill will and injustice and represents the cognitive component of the behavior. Using confirmatory factor analysis (CFA), Buss and Perry (1992) showed that they both are multidimensional four- factor model and a hierarchical factor model (four correlate with the first stated factors and reflect the second factor of general aggression), they fit to the data well. Moreover, using peer nomination procedure, Buss and Perry (1992) found reasonable positive correlations with the self-report measures. Several 
studies highlighted the psychometric quality of the 29-item AQ in different contexts (e.g. Archer, Holloway, \& McLoughlin, 1995; Fossati, Maffei, Acquarini, \& Di Ceglie, 2003; Condon, Morales-Vives, Ferrando, \& Vigil-Colet, 2006).

In Russian preschool institutions there are many teachers having latent national aggression. This aggression is not always related to the language, Russian or Tatar, Chuvash, Mari, it is mainly related to the individual national self-determination or to the religious affiliation. We have carried out our research of the latent national aggression among the university correspondence-course students in the Republic of Tatarstan, which is a constituent entity of the Russian Federation. The students were teachers at bilingual kindergartens with Russian-Tatar and Tatar-Russian environment. 1231 teachers were questioned. The research was held in 2012, 2013 and 2014. We have discovered that $63 \%$ of Tatar teachers have latent national aggression to Russians and $68.5 \%$ of Russian teachers have latent national aggression to Tatars. The determinants of latent national aggression were national enmity, distrust, disrespect, contempt and other states. This raises the problem: what psychological and pedagogical factors of educational process organization in higher educational institutions can neutralize the students' latent national aggression and provide effective tolerance development among children. There is a serious risk to social cohesion if countries neglect the need for educational equality for all.

The purpose of the research is to define the psychological and pedagogical conditions of neutralizing the latent national aggression among kindergarten teachers and to provide effective tolerance development among preschool children.

\section{The research tasks are:}

- to characterize the opinions of common people and teachers in the Volga Region of Russia (with dense habitation of the Tartars, the Baskirs, the Chuvashes, the Maries and other nationalities) to national aggression and developing tolerance in children;

- to determine the best age for developing tolerance and positive cross-cultural dialogue;

- to analyze national-regional specific features in educating preschool teachers for the system of preschool education in Russia;

- to work out the procedure of preventing national aggression among future preschool teachers.

\section{Materials and Methods}

The study used different questionnaires:

- inventory for aggression factors measurement-FAF (Hampel \& Selg, 1975);

- Picture-Frustration-Test PFT (Rosenzweig, 1957);

- Minnesota Multiphasic Personality Inventory- MMPI (Hathaway \& McKinley, 1951);

- EMI (Ullrich, 1977).

Buss-Durkey Inventory was developed by A. Buss and A. Durkey in 1957 and is intended for the diagnosis of aggressive and hostile reactions.

Buss and Durkey identified the following types of reactions:

1) Physical aggression is the use of physical strength against another person.

2) Displaced aggression is aggression referred to another person indirectly or not referred to anyone.

3) Exasperation is the willingness to exercise negative feelings at the slightest stimulation (hot temper, rudeness).

4) Negativism-oppositional manner in behavior from passive resistance to active struggle against the established customs and laws.

5) Resentment-envy and hatred of others for the real and fictitious actions.

6) Suspiciousness is in the range from distrust and caution against people to the belief that other people plan and do harm.

7) Verbal aggression is expressing negative feelings both in form (shout, scream), and in the content of verbal responses (curses, threats).

8) Feeling of guilt-expresses the belief of the subject that he/she is a bad person, that he/she acts evil, and also his/her perceived remorse.

Processing of the results and interpretation was carried out in 8 scales (table 1). 
Table 1. Questionnaire aimed at identifying hidden national aggression

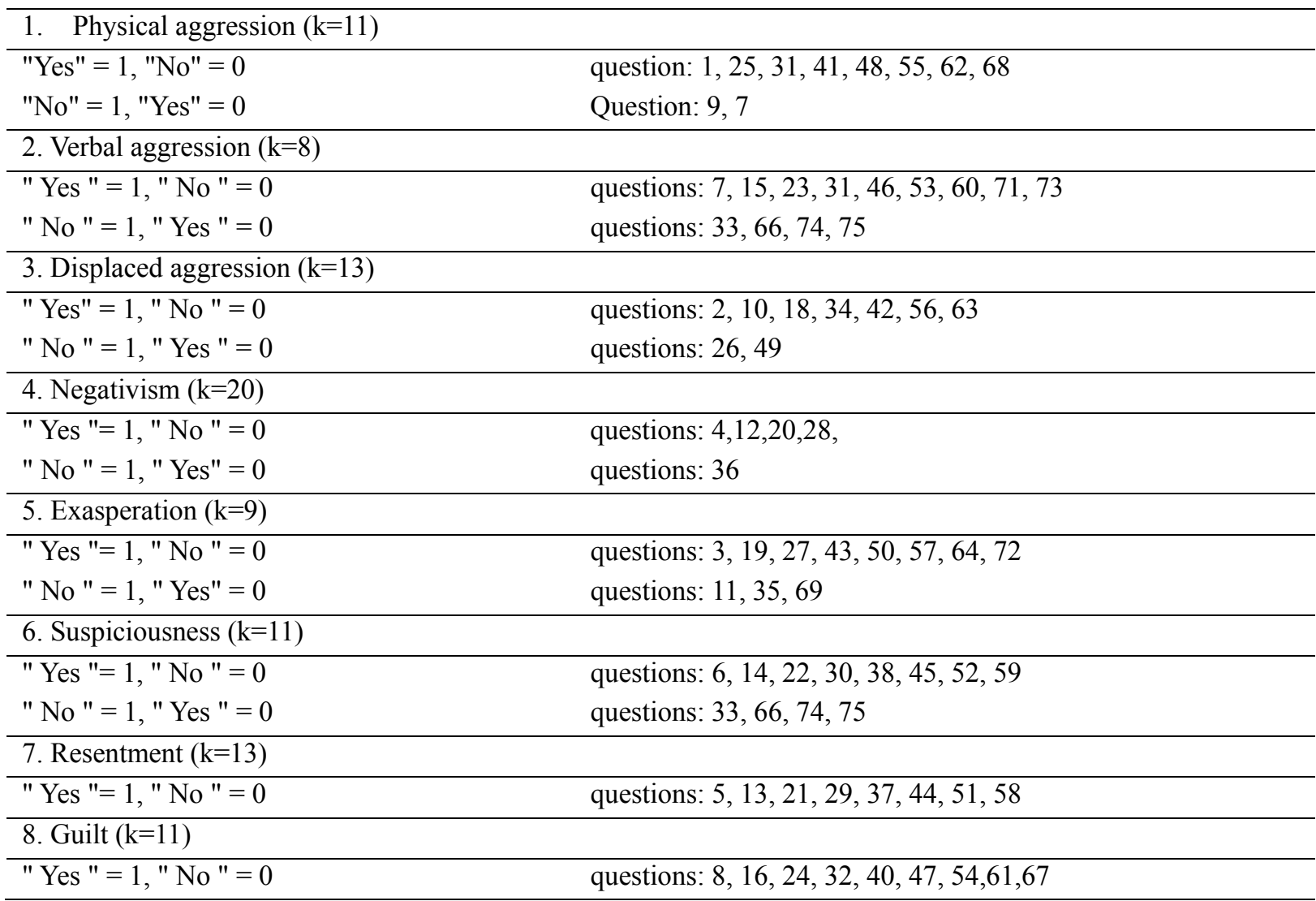

Index of aggressiveness included scales 1, 2 and 3; index of hostility included scales 6 and 7.

Normal aggressiveness is the value of the index equal to $21 \pm 4$, and normal hostility is $6-7 \pm 3$. The possibility of reaching a certain value is also considered. The value showed the level of aggressiveness demonstration.

The study concluded: personality and aggression as an act of behavior can be understood in the context of psychological analysis of a person motivation and interest, requirements. Therefore, the Buss-Durkey Inventory should be used together with other techniques: personality questionnaires (Cattell, Spielberg), projective techniques (Lüscher) etc.

\section{Results and Discussions}

\subsection{The Opinions of Common People and Teachers of Russia to National Aggression and Developing Tolerance in Children}

The Volga region is the central part of Russia in which several large nations live, including the Tartars, the Baskirs, the Chuvashes, the Mari, the Mordovians, the Udmurts. All these nations have their own national identity and official bilingualism in Russia.

The problem of national (racial, religious) aggression is usually discussed only when we face this aggression. The examples are assassinations in the USA (in the streets and in schools), the events in Western Europe (the slaughters in Norway, Great Britain), in Russia (terrorist attacks in Volgograd, mufti homicide and religious buildings arson in Tatarstan, confrontations with militants in the North Caucasus), in Ukraine (slaughter of peaceful people in Odessa, Slovyansk, Kramatorsk and so on). Surely, each of these incidents has also other reasons besides national. That is why journalists, lawyers, state security services, scholars study political, economic, national-cultural and other reasons. But no one examines psychological and pedagogical reasons.

Examining psychological and pedagogical reasons of national aggression (both latent and overt) requires not amateur but professional approach. Though political reasons are obvious due to mass media, psychological and pedagogical reasons have long-term effects. They are declared but are ignored by governments and society.

Our survey showed that people in the Volga region suppose that they all are skilled in the problems of education 
and education does not matter when we discuss the problems of national aggression prevention. Though the role of education is declared by all government institutions. Many states including Russia appropriate some funds for grants financing researches in education. But according to Russian teachers' opinion these researches are often declarative and formal $(76 \%)$ and only call for tolerance, civic consciousness and peaceful conversation of representatives of different nations, cultures, religious confessions (82\%). And these are the school teachers' answers to the question "at what age should we start to develop tolerance?": at primary school (age 7-10)-64,5\%, at junior high school (age 10-15)-21\%, at senior school (age 16-17)-7,5\%, at university (age 17-22)-4\%, at preschool (age 3-6)-3\%. Preschool teachers say that a child's development should start at the age of 3 (93,7\%). We see the difference between school teachers' and preschool teachers' opinions about the age. Only $3 \%$ of school teachers think that we should start to develop tolerance in little children and $93,7 \%$ of preschool teachers are sure this work should be started at kindergarten.

When identifying the respondents' nationality we considered not ethnic background but ethnocultural and language belonging: there are many people in Tatarstan who are Tatars by nationality but Russians by culture and character. That is why official figures stating that there are more Tatars in the Tatarstan Republic than Russians are not really correct: there are many Russified families in the republic and the figures grow year by year despite the efforts of the local government to save Tatar language as the second official language. The leaders of national movement call these families "mankurts" (betrayers of the nationality). About a half of Russified Tatars constitute themselves Tatars and have ethnic or even nationalist ideas. Another half, though of Tatar background, have Russian national consciousness and speak of famous people of Tatar-Bulgarian background (famous general Suvorov, general Kutuzov, classics of Russian literature Turgenev, Bulgakov and many others).

Parents gave the same answers as school teachers, they did not think about developing tolerance in preschool age, though their children visited kindergartens. However, these parents showed even more latent national aggression than the teachers. $66,3 \%$ of Tatar parents showed latent national aggression to Russians; $69,7 \%$ of Russian parents showed latent national aggression (the same parameter but Russian teachers to Tatars).

Six and seven years-old children displayed direct dependence of their attitude to positive and negative qualities of national fairy-tale characters on their parents' opinions: Tatar children $66,5 \%$, Russian children $69,8 \%$.

\subsection{The Best Age for Developing Tolerance and Positive Cross-cultural Dialogue}

Our researches (Gabdulchakov, 2011) show that basic principles of tolerance, respect to different cultures, interest to cross-cultural dialogue and even the principles of efficient bilingualism are developed not at school or university but in kindergarten at the age of 3-5, when parents and teachers play the special role in the life of children. Yet, in kindergarten children face negative unprofessional though unconscious influence.

For example, a teacher who follows separatists, may display his/her liking of nationalists and even extremists, or may develop tolerance and cross-cultural dialogue without following this interest herself. As a result, a preschool teacher transmits national aggression to children directly or latently (unconsciously). Children also take it in unconsciously but they sometimes program their behavior for the rest of their lives. There are many teachers of this kind in different bilingual regions of Russia.

Immigrants play great role in stirring up national aggression in Russia. For example, Steven Myers and Andrew Roth note in their article «Russia rounds up immigrants» (International Herald Tribune. Tuesday. August, 13. 2013) (Myers \& Roth, 2013): «In the days that followed, the police and immigration officials mounted raids at markets across Moscow, in factories that operated in the shadows of the law, in the city's subway system and on the streets. At last count nearly 1,500 foreigners have been detained, including about 600, most of them Vietnamese, who are now being held in a temporary tent camp more appropriate for a war zone or the scene of a natural disaster than the center of a capital disaster than the center of a capital city». Detaining such a large number of ineligible foreigners will surely draw anxiety and national aggression not only among immigrants, but also among their children. And these children will have this aggression the whole live. We can notice this situation in Moscow, Kazan and other cities of Russia in 2014 (Gabdulchakov, 2014).

\subsection{The Specific Features of Preschool Teacher Education in the Volga Region}

In the system of preschool teacher education in the Volga region and in other universities of Russia there is a pattern of forming multicultural, cross-cultural competence according to which a teacher should master this competence and transmit it to children developing cross-cultural tolerance, civic consciousness and love of country in them. And everybody (both the norms and the programs authors and the performers) takes as a premise that there is no national aggression in Russia. But real facts in Russia (terroristic acts, increase in the number of deviant teenagers, religious intolerance and others) militate against this. 
The contradiction between this pattern of preschool teacher and psychologist education (which declares moral values) and the existing practice in education (which has latent features of children's, parents' and teachers' national aggression) is evident. That is why it is necessary to work out the technology which will allow preventing national aggression among future teachers at universities, to make them competent to prevent this aggression not only in themselves, but also in children and their parents.

In other words, it is extremely necessary to work out the techniques, methods, means, psychological tools and didactic content of the technology of prevention national aggression during the professional education when teaching them psychology-pedagogical and methodic courses, pedagogical practice and also after-study time of occupational adaptation. Our researches (Valerian F. Gabdulchakov' 2014) show that this technology should consider national and regional features of Russia regions.

\subsection{The Technology of Preventing National Aggression among Future Preschool Teachers}

We have prepared the technology of preventing national aggression for teachers, who will be able to develop not nationalism but love in their students, tolerance cross-cultural dialogue. The idea of this technology is to use multicultural content based not on traditional pedagogical principles, but psychology-methodical principles which are new for university educational process. These principles are: unity of conscious and non-conscious in education, upbringing and development; communicative personality core; cross-cultural dialogue personification; anticipation, mediation, integration, attraction of multicultural content and others.

For example, our experiments show that anticipation intensifies student's personification in cross-cultural dialogue if the facilities for anticipation regulative component are provided in the educational process. That is if due to specific organization of a teacher and students' joint activities the students are able to take part in goal setting, planning their own activity and its control; if we ensure their predicting cross-cultural content, types and results of business and simulation games; if we consider the relation of regulative, cognitive and communicative components of anticipation during working out the methods of organization of structural stages of the game. This technology is not only kindergarten oriented. It is also family oriented, as it appeals to interaction between children and parents, teacher and parents.

\section{Conclusions}

Nowadays there are many researches on the theory and practice of multicultural education in Russian and world literature. Every region of Russia (Tatarstan, Chuvashia, Dagestan and others) has its own unique specific character. Many teachers possess sufficient level of cross-cultural competence but feel difficulty and refer to developing positive cross-cultural dialogue as a mere formality. Whereas multicultural education has dynamic character, it is hard to be fixed, education path varies constantly. From this perspective we tried to work out the technology which allows fixing the education and self-education path, it allows to organize educational work efficiently based on considering the variety of opinions, religious views, and ethnic features of all main subjects in educational process (Gabdulchakov, 2014).

Our experiments prove that the technology of prevention latent national aggression in university can be based on joint teacher's and student's work. In this regard the technology should give students the opportunity to participate in goal-setting, planning their pedagogical activity and its control; ensure their predicting cross-cultural content, types and results of business or simulation games; when developing the methods of organization of stages in the game it is necessary to consider the regulatory, cognitive and communicative components anticipation relationship. The technology should be based on multicultural content, which reveals the values of two cultures, two languages, which rehearses positive situations of cross-cultural dialogue.

For the present, the technology is oriented to the students of preschool department who also work at kindergartens. Therefore the action on children and their parents is only indirect (via kindergartner) and this action, its psychology and methodical tools require further research. Preschool teacher staff is also a source of concern. In recent years there have been many preschool teachers without psychology-pedagogical education in Russia's kindergartens. Due to the staff shortage employers are quite satisfied with any degree in higher education. As a result the quality of preschool education is poor. People, working in kindergarten because of closing down of the companies they had worked for, do not know the theory and teaching techniques reject regulatory requirements etc.

The purpose of multicultural education is to help students understand and determine cultural differences and similarities and to recognize the accomplishments of diverse ethnic, racial, and socio-economic groups. It is practice that hopes to transform the ways in which students are instructed by giving equal attention to the contributions of all the groups in a society. Special focus may be placed on minority groups that have been 
under-represented in the past (Nieto, 2004; Tiedt, 2005).

\section{References}

Banks, J. A., \& McGee, C. A. (2007). Multicultural education: Issues and perspectives (p. 491). Banks. Hoboken: Wiley.

Einarsdóttir, J., \& Perry, B. (2012). Young children's decisions about research participation: Opting out. International Journal of Early Years Education, 244-256.

Gabdulchakov, V. F. (2011a). Linguistic education in kindergartens. International Journal of Early Years Education, 19(2), 185-186.

Gabdulchakov, V. F. (2011b). The developing approach to training in the conditions of polycultural language formation. The collection: Scientific potential of the world (pp. 50-52). Przemysl.

Gabdulchakov, V. F. (2014). Communicative Core of Interaction and its Influence on Education Results. Procedia-Social and Behavioral Sciences. Third Annual International Conference "Early Childhood Care and Education», 146, 381-384.

Gabdulchakov, V. F. (2014a). Conscious and Unconscious in the Conditions of Educational Process. Procedia-Social and Behavioral Sciences. Third Annual International Conference «Early Childhood Care and Education», 146, 466-469.

Gabdulchakov, V. F. (2014b). Multicultural Language Development of Preschool Children in Russia Procedia-Social and Behavioral Sciences. Third Annual International Conference «Early Childhood Care and Education», 146, 222-225.

Gabdulchakov, V. F. (2014c). Personification of Multicultural Education in the Universities of Russia (Analysis of Training Specialists for Kindergartens) Procedia-Social and Behavioral Sciences. Third Annual International Conference «Early Childhood Care and Education», 146, 129-133.

Gabdulchakov, V. F. (2014d). Preparing to Work with Text in Kindergarten Procedia-Social and Behavioral Sciences. Third Annual International Conference «Early Childhood Care and Education», 146, 323-328.

Gabdulchakov, V. F. (2014e). The Problems of Language Personality Formation in Russia (the Analysis of Language Processes and Pedagogical Technologies) Procedia-Social and Behavioral Sciences. Third Annual International Conference "Early Childhood Care and Education», 146, 158-162.

Kudryavtsev, V. T. (2011). The phenomenon of child creativity. International Journal of Early Years Education, 45-53. http://dx.doi.org/10.1080/09669760.2011.570999

Myers, S., \& Roth, A. (2013). Russia rounds up immigrants. International Herald Tribune. Tuesday. August 13.

Nieto, S. (2004). Affirming diversity: The sociopolitical context of multicultural education (p. 464). Boston: Pearson Allyn \& Bacon.

Sleeter, C. E. (1996). Multicultural Education as Social Activism (p. 224). State University of New York Press.

Tiedt, P. L. (2005). Multicultural teaching: A handbook of activities, information, and resources (p. 406). Boston: Pearson/A\&B.

Veraksa, N. E. (2011). Development of cognitive capacities in preschool age. International Journal of Early Years Education, 79-87. http://dx.doi.org/10.1080/09669760.2011.571003

\section{Copyrights}

Copyright for this article is retained by the author(s), with first publication rights granted to the journal.

This is an open-access article distributed under the terms and conditions of the Creative Commons Attribution license (http://creativecommons.org/licenses/by/3.0/). 